\title{
Sizing of Power Electronics EMC Filters Using Design by Optimization Methodology
}

\author{
JL.Schanen, A.Baraston, M.Delhommais \\ G2ELab \\ University Grenoble Alps \\ CS 90624, 38031 Grenoble CEDEX 1 \\ jean-luc.schanen@g2elab.grenoble-inp.fr
}

\author{
P.Zanchetta \\ University of Nottingham, UK \\ D.Boroyevitch \\ CPES Virginia Tech, USA
}

\begin{abstract}
This paper proposes a synthesis of EMC filter design method for power electronics converters. It starts with the description of the legacy approach, using the usual Common Mode / Differential Mode decomposition, and underlines the need of symmetry and the associated limits. Then an illustration of a design by optimization process is provided in the case of a simple switching cell. Finally, a full system composed of a PFC rectifier is provided, using EMC filters on both $\mathrm{AC}$ and $\mathrm{DC}$ sides. This example requires a design by optimization, since the two filters exhibit strong interactions.
\end{abstract}

Keywords-Power Electronics, EMC, Design by Optimization

\section{INTRODUCTION}

Power Electronics can be seen as the major "enabling technology", which initiated the "More Electrical" trend of the XXI century. However, if the switching mode power conversion allows high efficiency and easy control of the electrical power, it also generates high frequency disturbances, especially due to harmonics of absorbed currents and voltage, and also to stray currents induced in the ground. The mitigation of these stray effects is mandatory in modern systems where all becomes "all electronic", with higher susceptibility to external noise. The "ElectroMagnetic Compatibility" vocabulary has been launched in the early 90's [1], and is today a mandatory step in converter design. EMC filters are a significant part of the weight and cost of a power converter, very often between $25 \%$ and $40 \%$ of the total converter [2]. The specificity of EMC filters of Power Electronics converter is that the design has to account for the high voltages and currents operated in the converter, therefore, design constraints are not only the attenuation of noise, but also limited losses and saturation for filter components. With the development of power electronics in embedded networks, as aircraft or automotive applications, the weight reduction becomes clearly a major challenge that has to be addressed. For instance, the first studies of More Electrical Aircraft have led to the conclusion that it was not so interesting in comparison with conventional hydraulic systems, due to the added weight of power electronics converters [3]. In this context, the EMC filters are obviously under concern, and have to be designed according to a minimum weight. Two parallel strategies can be defined: either technological integration, to reduce the filter weight by using new materials and technologies [4-5] or design by optimization, by trying to use at best given technologies and materials. This second approach will be proposed in this paper. Part II will start with the conventional way to design filters, and remind the basics notions used in EMC filter design. Part III will introduce the design by optimization concept for EMC filters, applied to a simple switching cell. Finally Part IV will present a full converter including two filters, which have to be designed simultaneously due to a strong interaction. The major advantage of design by optimization will be underlined in this case.

\section{Conventional Filter Design}

\section{A. Common Mode Differential Mode Separation}

EMC investigations and filter design widely uses the wellknown Common Mode (CM) Differential Mode (DM) separation. The mathematical definition of this specific EMC basis is reminded hereafter, according to the notations of Fig.1.

$$
\left[\begin{array}{l}
V_{D M} \\
I_{D M} \\
V C M \\
I_{C M}
\end{array}\right]=[P] \cdot\left[\begin{array}{l}
V_{1} \\
V_{2} \\
I 1 \\
I_{2}
\end{array}\right] \text { with }[P]=\left[\begin{array}{cccc}
1 & -1 & 0 & 0 \\
0 & 0 & \frac{1}{2} & \frac{-1}{2} \\
\frac{1}{2} & \frac{1}{2} & 0 & 0 \\
0 & 0 & 1 & 1
\end{array}\right]
$$

Fig. 1. Conventional quadrupole notations and link with $\mathrm{CM} / \mathrm{DM}$ basis

The main difference with conventional electrical dipole representation used by electrical engineers is to take into account the reference potential and the associated current $\mathrm{I}_{\mathrm{CM}}$. $\mathrm{V}_{\mathrm{DM}}$ is simply the natural voltage used between wires, and if $\mathrm{I}_{\mathrm{CM}}=0, \mathrm{I}_{\mathrm{DM}}$ becomes $\mathrm{I}_{1}$. As illustrated in [6], the main interest of this $\mathrm{CM} / \mathrm{DM}$ representation is that it allows solving the quadrupole equations using two uncoupled systems, corresponding to a dipole for CM and another dipole for DM, 
provided that the electrical circuit is symmetrical. This can be simply illustrated in Fig.2 and equation (2) \& (3). The link between $V_{1}, V_{2}$ and $I_{1}, I_{2}$ is clearly coupled since it is a quadrupole, and the expression of the same relation in the $\mathrm{DM} / \mathrm{CM}$ basis underlines that for a symmetrical circuit (i.e. $Z_{1}=Z_{2}$ ), the two equations (3) in $\mathrm{DM}$ and $\mathrm{CM}$ become decoupled.

$$
\left[\begin{array}{l}
I_{1} \\
I_{2}
\end{array}\right]=\left[\begin{array}{cc}
1 / Z_{12}+1 / Z_{1} & -1 / Z^{12} \\
-1 / Z_{12} & 1 / Z_{12}+1 / Z^{2}
\end{array}\right] \cdot\left[\begin{array}{l}
V_{1} \\
V_{2}
\end{array}\right]
$$

$\left[\begin{array}{l}I_{D M} \\ I_{C M}\end{array}\right]=\left[\begin{array}{cc}1 / 4 Z_{1}+1 / 4 Z_{2}+1 / 2 Z_{12} & 1 / 2 Z_{1}-1 / 2 Z_{2} \\ 1 / 2 Z_{1}-1 / 2 Z_{2} & 1 / Z_{1}+1 / Z^{2}\end{array}\right] \cdot\left[\begin{array}{c}V_{D M} \\ V_{C M}\end{array}\right]$

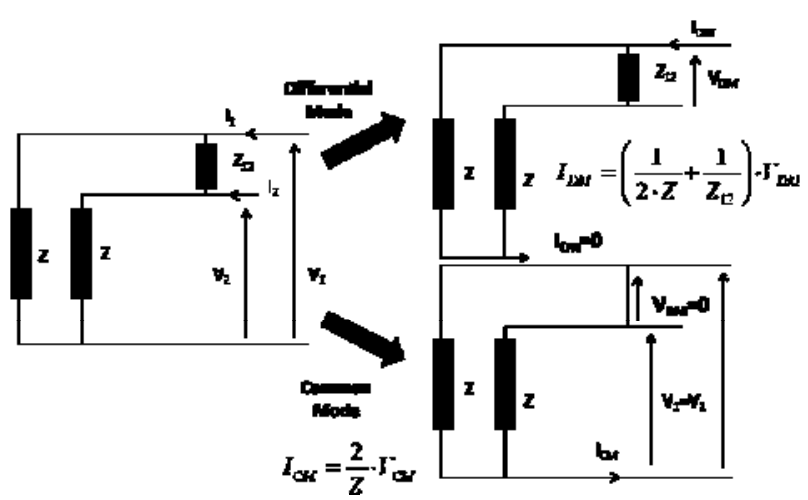

Fig. 2. Conventional quadrupole notations

In a more general case developed in [6], it is clearly shown that for a symmetrical link illustrated in Fig.3 (i.e. Z5 = Z6 and $\mathrm{Z} 2=\mathrm{Z3}$ ), the relations between input and output becomes decoupled if expressed in the CM/DM basis.

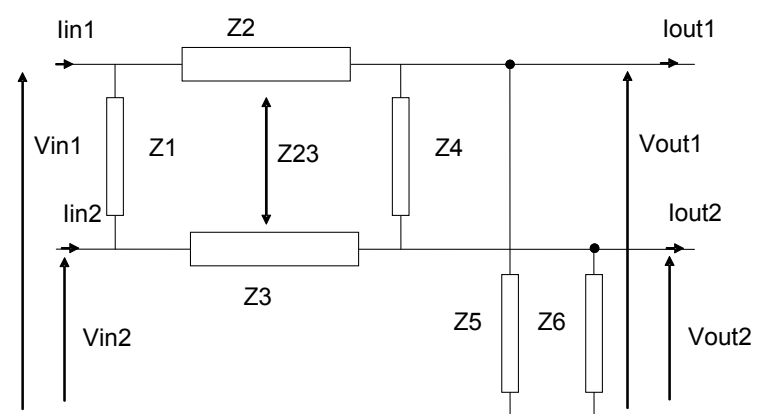

Fig. 3. Electrical link representation (from [6]). The relation between input and output becomes decoupled if symmetrical and expressed in CM/DM basis

Therefore, the CM/DM representation allows simplifying the study of the ElectroMagnetic Interferences (EMI), by solving only dipoles instead of quadrupoles, but it is crucial to keep symmetry of the electrical circuit.

\section{B. Filter topologies}

EMC filters for power electronics usually use simple second order filters. The topology of these filters depends on both converter and line impedances [7].
For DM filter, the topology supposes a low impedance on the converter side and a high one on the line side. Therefore, the topology is the one of Fig.4a. For CM filter, the converter impedance is supposed to by high, and the line one can be quite low, leading to the topology of Fig. $4 \mathrm{~b}$.

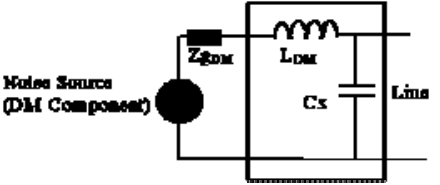

Fig. 4. a) typical DM filter

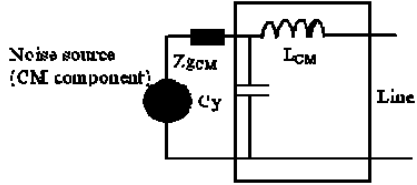

b) typical $\mathrm{CM}$ filter
The filter attenuation is defined by Eq. (4)

$A d B=20 . \log \left(\frac{V_{\text {line_without_Filter }}}{V_{\text {line_with_Filter }}}\right)$

With some assumption on converter impedances in DM and $\mathrm{CM}\left(\mathrm{Z}_{\mathrm{gDM}}=0, \mathrm{Z}_{\mathrm{gCM}} \gg \mathrm{Z}_{\text {line }}\right)$, both attenuations for $\mathrm{DM}$ and $\mathrm{CM}$ filters are given by Eq. (5) and Eq.(6) $\left(Z_{N}\right.$ being the Line impedance, represented by a Line Impedance Stabilization Network)

$A_{D M}=20 . \log \left(1+\frac{L_{D M}}{2 . Z_{N}} \cdot s+L_{D M} \cdot C x \cdot s^{2}\right)$

$A_{C M}=20 . \log \left(1+\frac{Z_{N}}{2} \cdot C y \cdot s+L_{C M} \cdot C y \cdot s^{2}\right)$

\section{Design methodology}

The legacy approach consists in measuring the EMI on the LISN, in the CM/DM basis, without any filter. These disturbances are compared to the required standard, in order to determine the desired attenuation on the whole frequency range. Then the cut-off frequency of the filters, both in DM and $\mathrm{CM}$, are adjusted to provide the needed attenuation. This design process is illustrated in Fig. 5 in the case of CM. In this figure, a $2 \mathrm{~kW}$ Buck converter has been considered (parameters given in Table I) and simulated using Pspice with a quite precise ElectroMagnetic environment (stray inductances, stray capacitances, Pspice models of components).

Once the cut off frequency has been found, the determination of the filters elements $\mathrm{L}$ and $\mathrm{C}$ depends on technological considerations. Very often, most of the filter weight and volume come from the magnetics [8], and therefore capacitances are increased. For $\mathrm{Cx}$ (DM), the limitation may be the bandwidth, due to esl (equivalent series inductor) which may be too large for big capacitances. For Cy (CM), safety issue arises due to the connection of these capacitors to metallic parts which are accessible to the users. In our example, $\mathrm{Cx}$ has been limited to $6.8 \mu \mathrm{F}$, and $\mathrm{Cy}$ (between power line and chassis) to $28 \mathrm{nF}$, according to $\mathrm{EN}$ 
501178, Annex A.5.2.8.2 table A1 (DC Voltage $=400 \mathrm{~V})$. These quite high values of capacitance lead to small values of magnetics (what was the objective). The discussion in part D will underline some limitations of this choice.

Last, the implementation on the CM and DM filters on the converters power lines has to guarantee the symmetry rule, therefore, the final scheme is the one depicted in Fig.6. The values of the line elements account for the splitting of each filter among the two lines, as well as for the coupling of magnetics between the two lines. This magnetic coupling is interesting to reduce the size of $\mathrm{CM}$ filter, and also allows avoiding the influence of DM inductance on $\mathrm{CM}$ one and vice versa. At this point, all filter components are supposed to be ideal, including the coupling. Obviously this will not be the case in real life, but it will not affect the global design of the filter, since these stray effects only impact the high frequency behavior. Only the unit magnetic coupling is too optimistic, but it can easily be taken into account when realizing the components, by modifying the desired inductances, accounting for the leakage inductances.

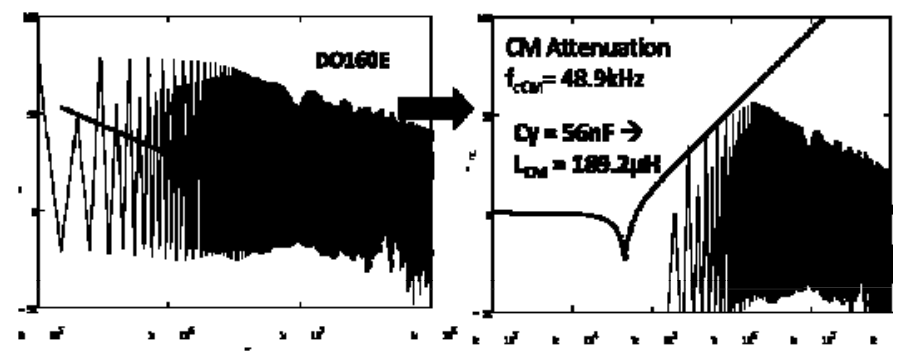

Fig. 5. Illustration of the desired attenuation and the choice of cut-off frequency in the case of CM for the Buck converter under study.

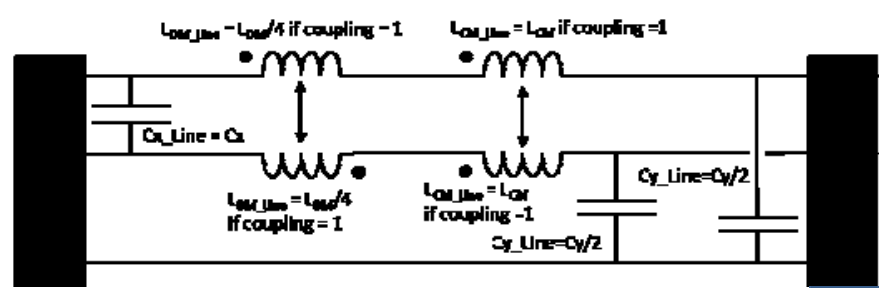

Fig. 6. Implementation of the $\mathrm{DM}$ and $\mathrm{CM}$ filter on the power lines, accounting for the necessary symmetry and the coupling of magnetics between lines.

\section{Limitations of the Conventional Method}

The legacy design method is based on the symmetrical realization of the filter. If, for instance the DM filter is not equally split among the two power lines, despite the good inductor and capacitor values for achieving the filter, the circulation of CM current generates different voltage drops on each part of the DM inductor, what creates additional DM noise. Moreover, the conventional design method supposes that the optimum corresponds to a maximization of the capacitors. In the considered example, this is not true. Indeed, the global weight of capacitors is evaluated to $50 \mathrm{~g}$ when the filter mass is $54 \mathrm{~g}$ ! There is thus another possible optimum to be found with increased inductances and lower capacitance.
Also, all attenuations have been obtained under the assumption that the converter impedances are either zero or very large in $\mathrm{DM}$ or $\mathrm{CM}$. When trying to obtain better performances in terms of weight for EMC filter, all these assumptions will perhaps no more be valid, and design by optimization must be more generic. This will be detailed in the next section.

TABLE I. CONVERTER AND FILTER PARAMETERS

\begin{tabular}{|c|c|c|c|}
\hline \multicolumn{4}{|c|}{ Power Converter } \\
\hline \multicolumn{2}{|c|}{ Power } & \multicolumn{2}{|l|}{$2 \mathrm{~kW}$} \\
\hline \multicolumn{2}{|c|}{ DC Input Voltage } & \multicolumn{2}{|l|}{$400 \mathrm{~V}$} \\
\hline \multicolumn{2}{|c|}{ DC Output Current } & \multicolumn{2}{|l|}{$10 \mathrm{~A}$} \\
\hline \multicolumn{2}{|c|}{ Switching Frequency } & \multicolumn{2}{|l|}{$100 \mathrm{kHz}$} \\
\hline \multicolumn{2}{|c|}{ Duty Cycle } & \multicolumn{2}{|l|}{0.5} \\
\hline \multicolumn{2}{|c|}{ Input Capacitor } & \multicolumn{2}{|c|}{$\begin{array}{l}\mathrm{Cin}=400 \mu \mathrm{F}, \\
\text { esl }=10 \mathrm{nH}, \text { esr }=0.2 \Omega\end{array}$} \\
\hline \multicolumn{4}{|c|}{ EMC Filter } \\
\hline \multicolumn{4}{|c|}{$\mathrm{F}_{\mathrm{cDM}}=37.7 \mathrm{kHz} \quad \mathrm{F}_{\mathrm{cCM}}=48.9 \mathrm{kHz}$} \\
\hline \multicolumn{2}{|c|}{$\mathrm{CM} / \mathrm{DM}$ basis } & \multicolumn{2}{|c|}{ Power Line Values } \\
\hline $\mathrm{L}_{\mathrm{DM}}$ & $2.6 \mu \mathrm{H}$ & L $\mathrm{L}_{\mathrm{DM} \text { Line }}$ & $\begin{array}{l}\text { 650nH } \\
\text { Coupling -1 }\end{array}$ \\
\hline $\mathrm{Cx}$ & $6.8 \mu \mathrm{F}$ & $\mathrm{C}_{\mathrm{x}_{-} \text {Line }}$ & $6.8 \mu \mathrm{F}$ \\
\hline $\mathrm{L}_{\mathrm{CM}}$ & $189.2 \mu \mathrm{H}$ & $\mathrm{L}_{\mathrm{CM} \_ \text {Line }}$ & $\begin{array}{l}189.2 \mu \mathrm{H} \\
\text { Coupling } 1\end{array}$ \\
\hline $\mathrm{Cy}$ & $56 \mathrm{nF}$ & $\mathrm{C}_{\mathrm{y}_{-} \text {Line }}$ & $28 \mathrm{nF}$ \\
\hline
\end{tabular}

III. Design by Optimization in a Simple CASE

\section{A. EMC Model of a Switching Cell}

The time domain simulation can be used to investigate the EMI from a power converter, as shown in the previous part. However, simulation time, memory space, convergence issues are often associated with this kind of simulations, and this is definitively not adapted to optimization. Therefore, the model of the switching cell in the frequency domain is preferred [9]. The idea of this modeling method is to replace the switching devices by equivalent sources, reproducing the voltage and current discontinuities. For the considered Buck converter, the equivalent circuit is given in Fig.7: the current source corresponds to the switch current and the voltage source to its voltage. These sources can be expressed in the frequency domain, either by a FFT of the switch signals (simulated or measured), or by approximating these waveforms with simple slopes and performing the Laplace transform of these sources. Then, the converter is associated with the filter to be designed and the LISN, and the disturbances can immediately be evaluated using the formal resolution of the equivalent circuit of Fig. 7 in the frequency domain.

\section{B. Optimization Principle}

The design methodology starts from technological description of the components: EMC filter inductors and capacitors are characterized by geometrical data and material properties, or interpolated from manufacturer datasheets. Then, electrical quantities, such as capacitance, inductance, 
but also maximum flux, maximum current density or rms current, ... are obtained thanks to analytical formulas. Voltage and current ripple are also evaluated, as well as EMC behavior using the equivalent circuit of Fig.7-bottom. Other additional constraints such as the cooling system of the semiconductors can be added, but will not be developed in this paper. The full optimization process is illustrated in Fig. 8. All models are implemented in a specific optimization framework developed in our lab [10].
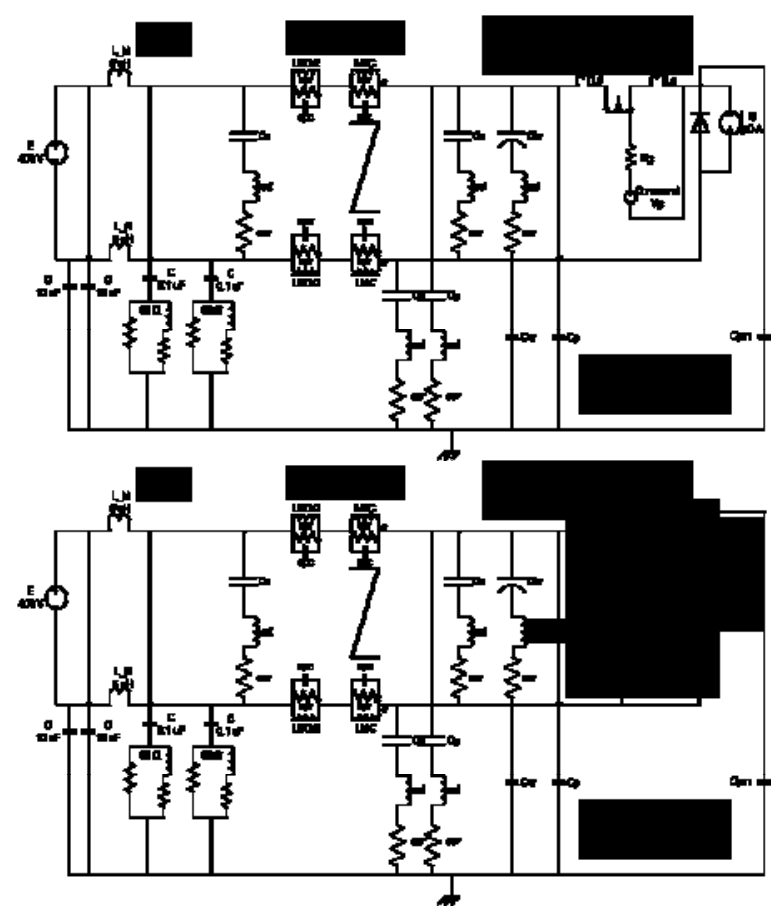

Fig. 7. Top: buck converter model - Bottom: Equivalent circuit for EMC studies.

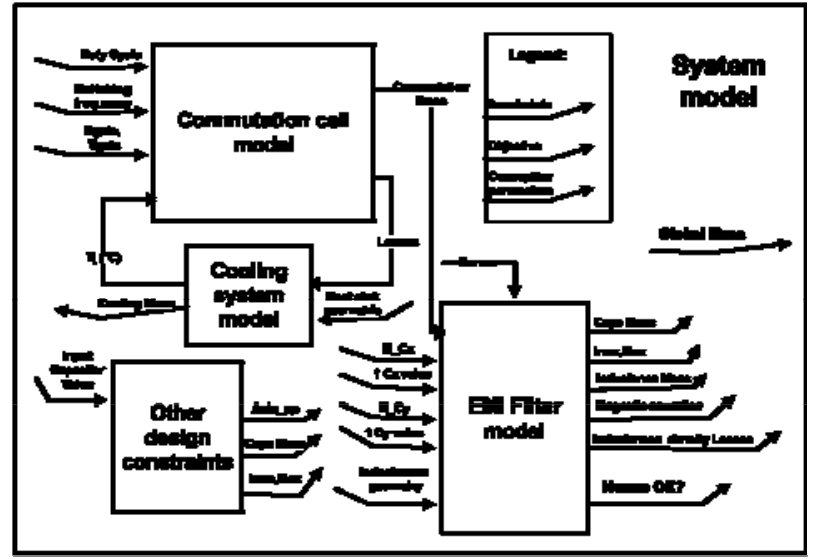

Fig. 8. Design methodology.

In reference to Fig.8, the cooling system has not been considered. The capacitor model is simply an interpolation of manufacturer datasheets, providing the weight of the capacitors as a function of the capacitance, for both technologies Cx and Cy (Fig. 9). Several capacitors can be associated in parallel if needed. As explained previously, the inductors are described using technological variables: a toroidal core is used, with homothetic variation (changing its heights - one of the design parameters- changes all other size), the turn number is also a design variable, as well as the wire diameter The magnetic material is fixed. Permeability has been chosen at 60 for DM inductor, and 5000 for CM one. To avoid any saturation, the maximum flux in the core is a constraint during the optimization process. For the Common Mode inductor, the peak flux results both from peak CM current and non-perfect coupling between the two wirings (leakage flux). The peak Common Mode current is evaluated using the equivalent frequency of the MOSFET voltage slope [4], and the leakage effect is taken into account using [11].
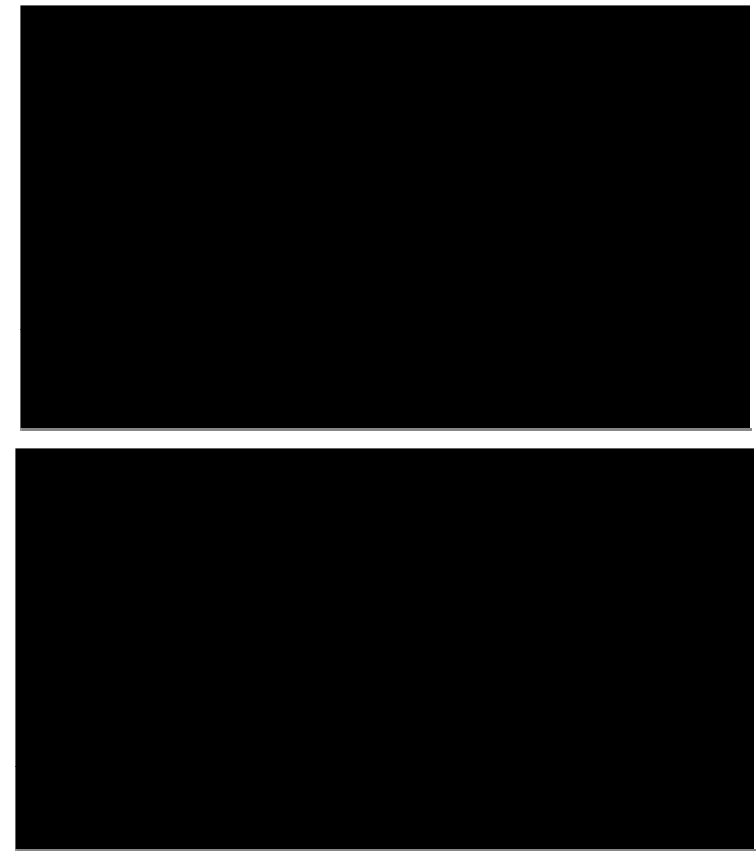

Fig. 9. Top: Interpolation for Weight vs Capacitance. Top: $\mathrm{Cx}-$ Bottom Cy

\section{Results}

The optimization of the proposed buck converter has been performed to respect all design criteria (maximum current density, saturation ...), including the EMC standard DO160E. The main optimization results are given in Table II. As stated in the discussion of the previous section, the optimal design does not anymore result in increasing the capacitors, since it has been shown that the magnetics were very small in the previous design. It is worth noting that the cut off frequencies for DM and CM has not changed a lot in comparison with the legacy design. Indeed, the considered converter is symmetrical; therefore, the mode separation assumption (what is the basis for legacy approach) is valid. Also the non-perfect coupling of the $\mathrm{CM}$ inductor replaces the DM filter (the leakage inductor of the designed $\mathrm{CM}$ filter is evaluated to $38 \mu \mathrm{H}$, which is sufficient for filtering the DM noise.

\section{Discussion}

The Design by Optimization performed in this simple application example shows that the optimum design does not correspond to the legacy approach. Of course, in this simple case, other approach may have provided more or less the same results, but it should be noticed that we kept the system simple 
in order to present the methodology. For instance the converter has been symmetrical, what avoids any mode coupling. Furthermore, the presented methodology only focused on EMC filter design, keeping all other parameters constant. The full methodology also applies by changing the switching frequency, the driver parameters, the input capacitor, ... but it is out of the scope of this paper. Next section will illustrate how the method can also be applied to a more complex topology: a three phases PFC rectifier with both input and output filters.

TABLE II. EMC FILTER LEGACY DESIGN AND OPTIMIZATION RESULTS

\begin{tabular}{|l|l|l|l|}
\hline \multicolumn{2}{|l|}{ Legacy design } & \multicolumn{2}{l|}{ Optimization Results } \\
\hline L $_{\text {DM_Line }}$ & $\begin{array}{l}650 \mathrm{nH} \\
\text { Coupling }-1\end{array}$ & L $_{\text {DM_Line }}$ & $\begin{array}{l}38 \mu \mathrm{H} \\
(\mathrm{CM} \text { leakage) }\end{array}$ \\
\hline $\mathrm{C}_{\mathrm{x}_{-} \text {Line }}$ & $6.8 \mu \mathrm{F}$ & $\mathrm{C}_{\mathrm{x}_{-} \text {Line }}$ & $467 \mathrm{nF}$ \\
\hline $\mathrm{L}_{\mathrm{CM} \_ \text {Line }}$ & $\begin{array}{l}189.2 \mu \mathrm{H} \\
\text { Coupling } 1\end{array}$ & $\mathrm{~L}_{\mathrm{CM} \_ \text {Line }}$ & $\begin{array}{l}479 \mu \mathrm{H} \\
\text { Coupling } 0.92 \\
\text { (computed) }\end{array}$ \\
\hline $\mathrm{C}_{\mathrm{y}_{-} \text {Line }}$ & $28 \mathrm{nF}$ & $\mathrm{C}_{\mathrm{y}_{-} \text {Line }}$ & $14.6 \mathrm{nF}$ \\
\hline Weight $55 \mathrm{~g}$ & & Weight: $13 \mathrm{~g}$ \\
\hline
\end{tabular}

\section{AppliCAtion to PFC RECTIFIER}

\section{A. Studied Converter}

In comparison with the previous example, the power range is completely different. We keep the aircraft application, but we try to design a converter between the HV AC grid and a HV DC grid. According to the system optimization presented in [12], the AC network voltage is fixed to $350 \mathrm{~V}-400 \mathrm{~Hz}$ and the DC voltage to $990 \mathrm{~V}$. The power is $120 \mathrm{~kW}$. The switching frequency is fixed to $40 \mathrm{kHz}$. The circuit is given in Fig. 10. It is worth noting that we decided to insert two different LISN, one at the input and one at the output. Indeed, even if it is not described in the DO160, we wanted to fix the EMC environment of this converter, and there is no specific load to plug on the DC side. Therefore, two LISN are the best way to provide a known environment for the EMC study of the converter. The boost inductors are fixed $(51.2 \mu \mathrm{H})$ according to current ripple, the output capacitor $(13.6 \mu \mathrm{F})$ according to voltage ripple. Some stray capacitances are added in order to be representative of $\mathrm{CM}$ noise generated by the converter. The floating points of the PFC legs (100pF) and the DC bus stray capacitance $(300 \mathrm{pF})$ are thus considered. The filter topology on the AC side and on the DC side are shown on Fig. 10.

\section{B. Manual Filter design}

Designing both input and output filters is not an easy task. Indeed, the $\mathrm{C}_{\mathrm{y}_{-} \mathrm{AC}}$ capacitors on the $\mathrm{AC}$ side may originate an additional $\mathrm{CM}$ current, especially if the boost inductors are non-perfect (i.e. exhibit a stray parallel capacitance). Therefore, if increasing these $\mathrm{C}_{\mathrm{y}_{-} \mathrm{AC}}$ reduces the disturbances measured on the AC LISN, it may increase the noise on the $\mathrm{DC}$ one. In the same idea, increasing the $\mathrm{C}_{\mathrm{y}_{\mathrm{D}} \mathrm{DC}}$ capacitors reduces the high frequency impedance on the $\mathrm{DC}$ side and thus may increase the $\mathrm{CM}$ current on the AC side [12-13]. Therefore, both DC and AC filters have coupled effects on both noise on DC and AC LISN, and therefore should be designed simultaneously. To perform the design, we fixed all capacitors to the maximum allowed values and used the trial and error method with a time simulation software, varying the $\mathrm{CM}$ and $\mathrm{DM}$ inductors (DC and $\mathrm{AC}$ ) until we fulfilled the DO160F on both AC and DC sides. Table 3 shows the obtained results.

TABLE III. EMC FILTER MANUAL DESIGN FOR PFC

\begin{tabular}{|l|l|l|l|}
\hline \multicolumn{2}{|l|}{ AC side } & DC side \\
\hline $\mathrm{L}_{\mathrm{DM} \_\mathrm{AC}}$ & $350 \mu \mathrm{H}$ & $\mathrm{L}_{\mathrm{DM} \_\mathrm{DC}}$ & $614 \mu \mathrm{H}$ \\
\hline $\mathrm{C}_{\mathrm{x}_{-} \mathrm{AC}}$ & $1 \mu \mathrm{F}$ & $\mathrm{C}_{\mathrm{x}_{-} \mathrm{DC}}$ & $500 \mathrm{nF}$ \\
\hline $\mathrm{L}_{\mathrm{CM} \_ \text {AC }}$ & $200 \mathrm{mH}$ & $\mathrm{L}_{\mathrm{CM} \_\mathrm{DC}}$ & $180 \mathrm{mH}$ \\
\hline $\mathrm{C}_{\mathrm{y}_{-} \mathrm{AC}}$ & $8 \mathrm{nF}$ & $\mathrm{C}_{\mathrm{y}_{-} \mathrm{DC}}$ & $8 \mathrm{nF}$ \\
\hline \multicolumn{4}{|c|}{ Total Weight: $98.88 \mathrm{~kg}$} \\
\hline
\end{tabular}

\section{EMC equivalent circuit and optimization models}

In order to use the Design by Optimization method, we have to provide models for all physical phenomena to be taken into account. We used exactly the same models as in the previous section (just adapting the boundaries for the core size, and the manufacturer datasheets for capacitor interpolation).

Regarding EMC model, we used the same approach as presented in section III, representing all current/voltage variations by equivalent sources. As a result, three voltage sources are replacing the three bottom switches of the three PFC legs, whereas one single current source allows reconstructing the DC current exciting the DC output capacitor and the DC circuit (including the DC filter, stray elements and DC LISN). The equivalent circuit is depicted in Fig. 12.

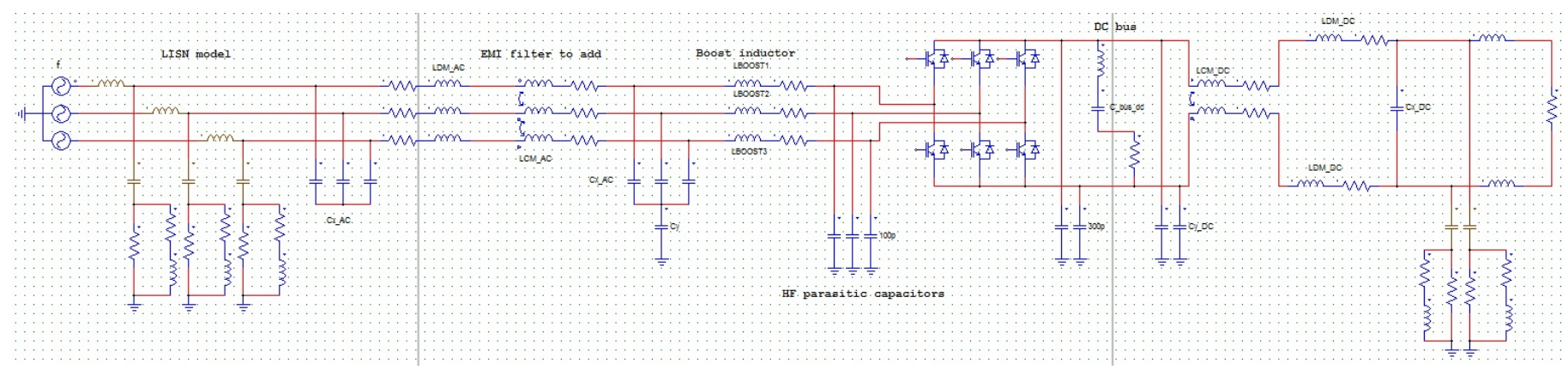

Fig. 10. Circuit description of the PFC with the two LISN and the two filters 


\section{Optimization Results}

Results are provided in Table IV. To facilitate comparison, we kept the capacitors identical and just optimized the inductors. Obviously, a full optimization is feasible. The optimization result shows an improved global weight. The DM inductors are so small that they are part of the Common Mode inductors (using the leakage). As shown in Fig.11, the EMC constraints are respected, on both $\mathrm{DC}$ and $\mathrm{AC}$ side, and the EMC model used (CADES in Fig. 11) exhibit a good agreement with the time simulation software. With this result, the Design by Optimization method is validated on a complex case, and shows a quick convergence to more or less the same optimal point as the one obtained after a long and boring trial and error method. Furthermore, additional degrees of freedom can be considered, as filter capacitors, switching frequency... what would lead to more global results.

TABLE IV. EMC Filter MANUAL DESIGN FOR PFC

\begin{tabular}{|l|l|l|l|}
\hline \multicolumn{4}{|c|}{ EMC Filter } \\
\hline AC side & DC side \\
\hline $\mathrm{L}_{\mathrm{DM} \_\mathrm{AC}}$ & $\begin{array}{l}486 \mu \mathrm{H} \\
(\text { leakage of CM) }\end{array}$ & L $\mathrm{DM} \_\mathrm{DC}$ & $\begin{array}{l}540 \mu \mathrm{H} \\
(\text { leakage of CM) }\end{array}$ \\
\hline $\mathrm{C}_{\mathrm{x}_{-} \mathrm{AC}}$ & $1 \mu \mathrm{F}$ & $\mathrm{C}_{\mathrm{x} \_\mathrm{DC}}$ & $500 \mathrm{nF}$ \\
\hline $\mathrm{L}_{\mathrm{CM} \_\mathrm{AC}}$ & $236 \mathrm{mH}$ & L $_{\mathrm{CM} \_\mathrm{DC}}$ & $170 \mathrm{mH}$ \\
\hline $\mathrm{C}_{\mathrm{y}_{-} \mathrm{AC}}$ & $8 \mathrm{nF}$ & $\mathrm{C}_{\mathrm{y} \_\mathrm{DC}}$ & $8 \mathrm{nF}$ \\
\hline \multicolumn{3}{|c|}{ Total Weight: $90.36 \mathrm{~kg}$} \\
\hline
\end{tabular}
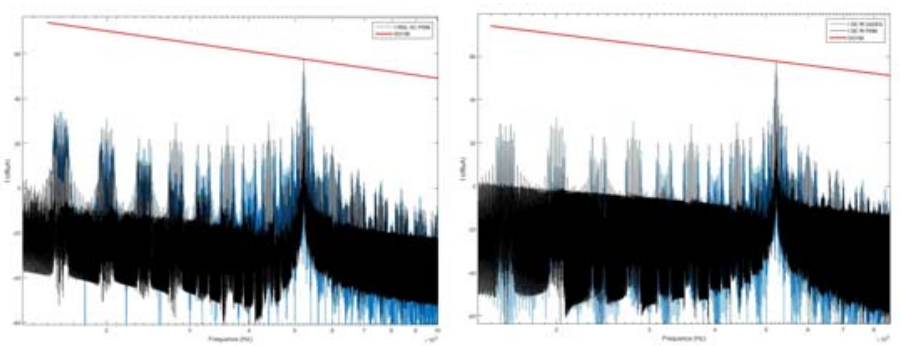

Fig. 11. AC and DC noise in comparison with the DO160F standard after optimal design of the filter

\section{CONCLUSION}

Design by Optimization method has been presented in the case of EMC filter design, and compared to legacy approach. This new way of design is promising, since it allows avoiding all usual assumptions, such as "capacitors are negligible compared to magnetics", or the usual CM/DM separation, which may be wrong for non-symmetrical topologies. It does also not consider any assumption for converter impedance. EMC models in the frequency domain are useful for this task, using other analytical models for taking into account other physical constraints associated with components design. All these models have been implemented in a specific framework, dedicated to optimization. This avoids many programming efforts and expertise in optimization, in order to conduct such a design method.

\section{References}

[1] D. N. Heirman, "A History of the Evolution of EMC Regulatory Bodies and Standards", 16th International Zurich Symposium on Electromagnetic Compatibility, February 2005.

[2] Boroyevich, Dushan; Zhang, Xuning; Bishinoi, Hemant; Burgos, Rolando; Mattavelli, Paolo; Wang, Fred, "Conducted EMI and Systems Integration”, CIPS 2014 8th International Conference, Nürenberg, 2014

[3] EU project MOET: http://www.transport-research.info/project/moreopen-electrical-technologies

[4] F.Mesmin, "Materiaux magnetiques et solutions innovantes de filtrage CEM pour applications aeronautiques", PHD dissertation, University Grenoble Alps, 28 sept 2012 (in French)

[5] Ali, M.; Labouré, E.; Costa, F.; Revol, B., "Design of a Hybrid Integrated EMC Filter for a DC-DC Power Converter", IEEE Transactions on Power Electronics, 2012, Volume: 27, Issue: 11

[6] De Oliveira Thomas, Mandray Sylvain, Guichon Jean-Michel, Jean-Luc Schanen, Adrian Perregaux "Reduction of conducted EMC using busbar stray elements" IEEE APEC'09, Feb. 2009, Washington DC, USA

[7] M. L. Nave, 3Power Line Filter Design for Switch-Mode Power Supplies", Van Nostrand Reinold, 1991, pp. 210

[8] Yoann Y. Maillet, "High-Density Discrete Passive EMI Filter Design for Dc-Fed Motor Drives", MsC dissertation Virginia Polytechnic Institute and State University, August 2008

[9] B. Revol, J. Roudet, J.L. Schanen, P.Loizelet, "EMI study of a three phase inverter-Fed Motor Drives", IEEE trans on IAS, Vol $47 \mathrm{n}^{\circ} 1$ January/Feb 2011, pp 223 - 231

[10] http://www.vesta-system.fr/en/products/vestacades/

[11] M. J. Nave, "On modeling the common mode inductor," in Proc. IEEE Int. Symp. Electromagn. Compat., 1991, pp. 452-457

[12] B.Wen, X.Zhang, F.Effah, A.Baraston, P.Zanchetta, D.Boroyevich, JL.Schanen, R.Burgos, P.Wheeler, A.Tardy, "Integrated Design by Optimization of Electrical Power Systems for More Electric Aircraftl", MEA 2015, February 3-5 2015, Toulouse, France

[13] Jettanasen, C.; Costa, F.; Vollaire, C.; Revol, B.; Morel, F., "Measurements and Simulation of Common Mode Conducted Noise Emissions in Adjustable-Speed AC Drive Systems", EMC Zurich 2009

[14] Tallam, R.M.; Skibinski, G.L.; Shudarek, T.A.; Lukaszewski, R.A., "Integrated differential-mode and common-mode filter to mitigate the effects of long motor leads on AC drives", ECCE 2010 Pages: 838 - 845

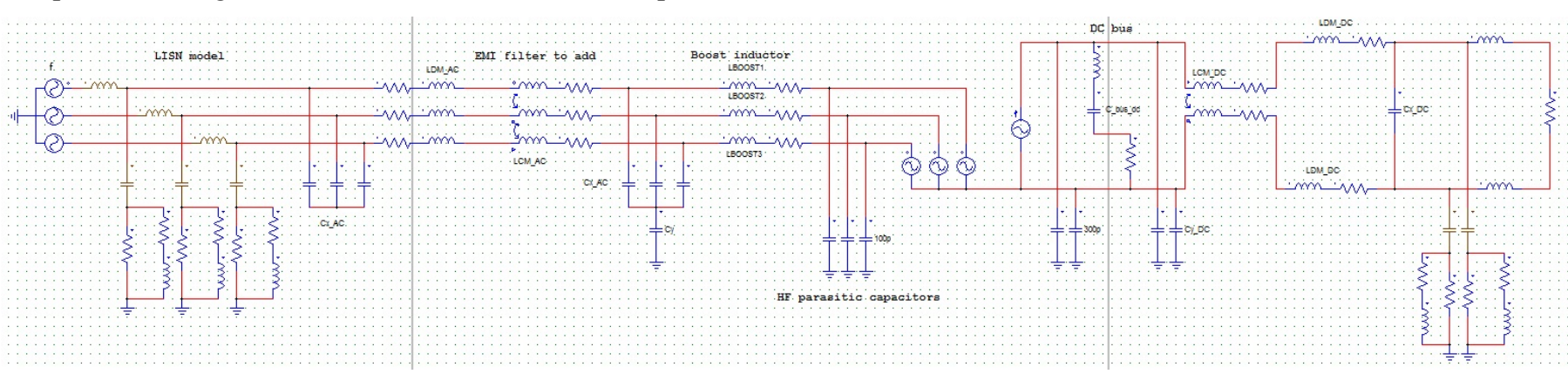

Fig. 12. Equivalent circuit of the PFC for EMC modelling 